\title{
Pregnancy outcomes in patients with a fontan circulation and proposal for a risk-scoring system: single centre experience
}

\author{
Sayqa Arif ${ }^{*}$, Aliyah Chaudhary ${ }^{1}$, Paul F. Clift ${ }^{1}$, R. Katie Morris ${ }^{2,3}$, Tara J. Selman², Sarah E. Bowater ${ }^{1}$, \\ Lucy E. Hudsmith', Peter J. Thompson ${ }^{2}$ and Sara A. Thorne ${ }^{1}$
}

\begin{abstract}
Background: Pregnancy in women with Fontan physiology poses a significant management challenge and is deemed high risk. The aim of this study is to describe short and long-term pregnancy outcomes in women who have undergone Fontan palliation and propose a novel risk-stratification model specific to women with a Fontan heart.

Methods: We undertook a single-centre, retrospective cohort study of all female Fontan patients $(n=78)$ from 1991-2015. We recorded pregnancy outcome, maternal cardiovascular and obstetric complications and fetal outcome. We propose a risk stratification model to identify those women who might be at highest risk of adverse outcomes during pregnancy.

Results: Twenty-one women had 55 pregnancies, with 13 (24\%) live births and 38 (69\%) spontaneous miscarriages $(p<0.001)$. Eight $(62 \%)$ out of 13 live birth pregnancies incurred maternal cardiovascular complications and six $(46 \%)$ experienced maternal obstetric complications. Median gestational age at delivery was 32(27-39) weeks with 12 out of 13 (92\%) pregnancies resulting in pre-term delivery. There were more pregnancies (OR 4.90, 95\% Cl 1.46-16.42, $p \leq 0.01$ ) and a trend towards a higher proportion of live births (OR 7.60,95\% Cl 1.81-31.97, $p=0.06)$, in the 'lower risk' compared to those women in the 'very high risk' group. There were no maternal deaths.

Conclusions: We observed a high first trimester miscarriage rate, significant maternal cardiovascular and obstetric complication rates and a high rate of pre-term births in pregnant Fontan women. Our risk stratification model requires further investigation but may identify those women at particularly high risk of a poor outcome, and inform realistic pre-pregnancy counselling.
\end{abstract}

Keywords: Fontan, fertility, pre-pregnancy counselling, pregnancy outcome

\section{Background}

The creation of a Fontan circulation has improved life expectancy for people born with functionally single ventricle congenital heart disease (CHD). However, the lack of a sub-pulmonary ventricle results in a chronic low cardiac output $(\mathrm{CO})$ state with pulmonary blood flow dependent on adequate preload [1]. Patients often encounter complications in adulthood with a gradually declining functional capacity, atrial arrhythmias, myocardial

\footnotetext{
* Correspondence: sayqaarif@doctors.org.uk

'Queen Elizabeth Hospital Birmingham NHS Trust, Birmingham B15 2TH, UK Full list of author information is available at the end of the article
}

dysfunction, thrombo-embolic events and hepatic dysfunction [2]. Reports suggest that the current UK single ventricle population is 1040 adults and 1700 children, with an expected increase in adult numbers by $60 \%$ in the next decade [3]. This improvement in survival to adulthood has resulted in an increased number of women with a Fontan circulation reaching child-bearing age.

Pregnancy is associated with considerable physiological stress. The normal heart can increase heart rate and stroke volume to adapt to changes in systemic vascular resistance and blood volume [4]. Patients with a Fontan circulation tolerate preload changes poorly, and their 
ability to increase $\mathrm{CO}$ is limited. Consequently, pregnancyrelated haemodynamic changes confer a considerable burden on the Fontan heart [5].

Published data regarding pregnancy in Fontan patients consists largely of small case series, as described in Table 1 [6-13]. Maternal cardiovascular morbidity, primarily due to atrial arrhythmias and deterioration of functional status has been observed. The rate of spontaneous miscarriages varied (27-65\%) may have been underestimated in some of the series $[6,10]$. Moreover, a significant proportion of pregnancies $(69-81 \%)$ resulted in premature births in the contemporary series $[7,8,10]$. Drenthen et al. and Cannobio et al. advised against pregnancy in these women, whereas more contemporary literature suggests that despite the comorbidities associated with the Fontan circulation, women can undergo pregnancy, albeit at the risk of encountering significant maternal morbidity [6-9].

We sought to determine the immediate and long-term outcomes of pregnancy within a large single-centre Fontan population. The main objective was to identify pregnancy outcomes, maternal cardiovascular morbidity and mortality, obstetric complications and fetal outcomes.

Current risk calculators such as CARPREG, ZAHARA and the modified WHO criteria either do not include women with a Fontan circulation, or simply classify them as high risk [14-17]. The CARPREG classification included women with both acquired and congenital heart disease and assigns a point for each predictor (prior cardiac event, New York Heart Association functional class $>$ II or cyanosis, left heart obstruction, left ventricular ejection fraction $<40 \%$ ). A score of 1 confers a $27 \%$ risk of maternal cardiovascular complications and a score $>1$ confers a $75 \%$ risk [14]. The ZAHARA study also identified predictors of adverse maternal events, in patients with congenital heart disease [17]. The modified WHO criteria include specific cardiac lesions in addition to clinical cardiac status. It applies to women with acquired as well as congenital heart disease and the risk categories range from low risk (group I) to a very high risk (group IV) $[15,16]$.

Table 1 Summary of published series reporting pregnancies in women with Fontan hearts

\begin{tabular}{|c|c|c|c|c|c|c|c|c|c|}
\hline Author & & $\begin{array}{l}\text { Zentner } \\
\text { et al }\end{array}$ & $\begin{array}{l}\text { Cauldwell } \\
\text { et al }\end{array}$ & $\begin{array}{l}\text { Gouton } \\
\text { et al }\end{array}$ & $\begin{array}{l}\text { Pundi } \\
\text { et } \mathrm{al}^{\mathrm{a}}\end{array}$ & $\begin{array}{l}\text { Drenthen } \\
\text { et al }\end{array}$ & $\begin{array}{l}\text { Hoare } \\
\text { and Radford }\end{array}$ & Sui et al & $\begin{array}{l}\text { Cannobio } \\
\text { et al }\end{array}$ \\
\hline Year & & 2016 & 2016 & 2015 & 2015 & 2006 & 2001 & 2002 & 1996 \\
\hline $\begin{array}{l}\text { Type of } \\
\text { study }\end{array}$ & & $\begin{array}{l}\text { Multi-centre } \\
\text { registry }\end{array}$ & $\begin{array}{l}\text { Single-centre } \\
\text { registry }\end{array}$ & $\begin{array}{l}\text { Multi-centre } \\
\text { registry }\end{array}$ & $\begin{array}{l}\text { Single-centre } \\
\text { registry }\end{array}$ & $\begin{array}{l}\text { Multi-centre } \\
\text { registry }\end{array}$ & & $\begin{array}{l}\text { Multi-centre } \\
\text { prospective } \\
\text { registry }\end{array}$ & $\begin{array}{l}\text { Multi-centre } \\
\text { registry }\end{array}$ \\
\hline Location & & $\begin{array}{l}\text { Australia/ } \\
\text { New Zealand }\end{array}$ & UK & France & USA & $\begin{array}{l}\text { Holland/ } \\
\text { Belgium }\end{array}$ & Australia & Canada & USA \\
\hline \multirow[t]{6}{*}{$\begin{array}{l}\text { Pregnancy } \\
\text { outcomes }\end{array}$} & $\begin{array}{l}\text { No. of } \\
\text { pregnancies }\end{array}$ & 40 & 43 & 59 & 70 & 10 & 4 & 5 & 33 \\
\hline & $\begin{array}{l}\text { Spontaneous } \\
\text { miscarriages }\end{array}$ & $9(39 \%)$ & $28(65 \%)$ & $16(27 \%)$ & $35(50 \%)$ & $5(50 \%)$ & - & - & $13(39 \%)$ \\
\hline & Terminations & $7.5 \%$ & & $4(7 \%)$ & $6(9 \%)$ & $1(10 \%)$ & - & - & $5(15 \%)$ \\
\hline & Live births & $15(38 \%)^{b}$ & 14 & $39(66 \%)^{b}$ & $29(41 \%)$ & $4(40 \%)$ & 4 & 5 & $15(46 \%)$ \\
\hline & $\begin{array}{l}\text { No. of } \\
\text { women } \\
\text { with live } \\
\text { births }\end{array}$ & - & 8 & - & - & 3 & 3 & 3 & 14 \\
\hline & $\begin{array}{l}\text { Maternal } \\
\text { deaths }\end{array}$ & 0 & 0 & 0 & 0 & 0 & 0 & 0 & 0 \\
\hline \multirow[t]{2}{*}{$\begin{array}{l}\text { Maternal } \\
\text { Complications }\end{array}$} & CVS & $\begin{array}{l}\text { 1/14 - } \\
\text { arrhythmia }\end{array}$ & $\begin{array}{l}5 / 14(36 \%)-4 \\
\text { arrhythmias and } 1 \\
\text { thromboembolism }\end{array}$ & $\begin{array}{l}6 / 59(10 \%) \\
\text { women had } \\
\text { CVS events - } 3 \\
\text { arrhythmias, } 3 \\
\text { heart failure }\end{array}$ & $\begin{array}{l}7 \text { women } \\
\text { had } \\
\text { arrhythmia }\end{array}$ & $\begin{array}{l}1 \text { woman AF } \\
\text { and } 2 \text { women } \\
\text { had decline in } \\
\text { NYHA class }\end{array}$ & $\begin{array}{l}2 \text { women - } \\
\text { arrhythmia } \\
\text { and heart } \\
\text { failure }\end{array}$ & - & $\begin{array}{l}3 \text { women }-1 \\
\text { heart failure, } \\
1 \text { valvular } \\
\text { regurgitation } \\
\text { and } 1 \mathrm{SVT}\end{array}$ \\
\hline & Obstetric & $7 / 14$ & 7/14 (50\%) PPH, & $3 \mathrm{APH} ; 2 \mathrm{VTE}$ & - & $1 \mathrm{PPH}$ & - & - & None \\
\hline \multirow[t]{2}{*}{$\begin{array}{l}\text { Fetal } \\
\text { outcomes }\end{array}$} & $\begin{array}{l}\text { Preterm } \\
\text { delivery }\end{array}$ & & 10/14 (71\%) & $25 / 36(69 \%)^{a}$ & $18 / 22(81 \%)^{a}$ & $2(50 \%)$ & $4(100 \%)$ & - & $1(7 \%)$ \\
\hline & $\begin{array}{l}\text { Gestation } \\
\text { length } \\
\text { (weeks) }\end{array}$ & 31.5 & 34 (range 29-40) & $34.0 \pm 4.0$ & $33.1 \pm 4.0^{\mathrm{a}}$ & - & $\begin{array}{l}31 \text { (range } \\
26-35 \text { ) }\end{array}$ & - & $\begin{array}{l}38 \text { (range } \\
28-40)\end{array}$ \\
\hline
\end{tabular}

${ }^{a}$ Data incomplete; ${ }^{b}$ includes one twin pregnancy. CVS cardiovascular, NYHA New York Heart Association functional classification, $P P H$ post-partum haemorrhage, APH ante-partum haemorrhage, VTE venous thromboemolism 
In this study, we also sought to identify factors that may confer increased maternal cardiovascular risk and propose a novel risk stratification model specific to women with a Fontan circulation to help identify those women at highest risk of suffering an adverse outcome during pregnancy.

\section{Methods}

\section{Study design and patient population}

A total of 98 women out of 224 Fontan patients were identified from our database of Adult Congenital Heart Disease (ACHD) patients at this Regional Tertiary ACHD Centre. Three women were subsequently followed-up elsewhere, two patients underwent cardiac transplantation prior to pregnancy, three patients were post-menopausal on referral to our unit and 12 patients died due to non-pregnancy related causes. A total of 78 women were included in the analysis.

A retrospective case review was undertaken of all the women with a Fontan circulation who were managed under the care of the combined Cardiology/Obstetric service from January 1991 to December 2015. Medical records from both the ACHD unit at the Queen Elizabeth Hospital Birmingham and the obstetric records from the Birmingham Women's Hospital were examined.

Baseline data collection included underlying cardiac anatomy, details of Fontan repair, New York Heart Association (NYHA) functional status defined as class I - IV [18], resting oxygen saturations, ventricular function defined as good, mild, moderate or severe impairment [19], and Fontan-related complications sustained cardiac arrhythmias, hepatic dysfunction, thromboembolism, protein-losing enteropathy and plastic bronchitis. Systemic ventricular function was determined by echocardiography using a series of measurements including qualitative assessment, ejection fraction (EF) using single-plane endocardial tracings, M-mode, spectral Doppler and tissue Doppler derived indices for assessment of systemic ventricular function, as described elsewhere [19]. Where ejection fraction was calculated, the British Society of Echocardiography grading was used to determine the degree of impairment- normal ( $E F \geq 55 \%$ ), mild impairment (EF 45-54\%), moderate impairment (EF 36-44\%) and severe impairment $(E F \leq 35 \%)$ [20]. For those women who became pregnant, complications prior to the first pregnancy were taken as baseline data. The neverpregnant Fontan patients were sub-divided into two age groups $-<25$ years and $\geq 25$ years. This age cutoff was chosen as the likelihood of women under the age of 25 years not having a pregnancy may have been more likely to be the result of social and personal factors rather than ill health.
We proposed a novel risk-stratification model specific to women with a Fontan circulation based on their preexisting cardiovascular morbidity at the time of prepregnancy counselling. Women were divided into three groups, based on their pre-pregnancy cardiovascular status (Table 2). We used predictors of poor outcomes in Fontan patients and data from the modified WHO criteria, which is considered to be the best available pregnancy risk calculator in women with CHD [15, 16, 20-22]:-

(1) Lower risk - women with good functional class (NYHA I) with no previous Fontan-related complications (as described above), resting oxygen saturation $\geq 94 \%$, normal or mildly impaired exercise capacity defined by peak myocardial oxygen consumption $\left(\mathrm{MVO}_{2}\right)$ on exercise $\geq 60 \%$ predicted, good ventricular function and no/mild atrio-ventricular valve regurgitation (AVVR).

(2) Intermediate risk - women with at least one of NYHA class II symptoms, treated Fontan-related complication (previous single, sustained arrhythmic event and/or thrombo-embolic complication with no recurrence at time of pregnancy), resting oxygen saturation 90-93\%, at least moderately impaired exercise capacity defined by $\mathrm{MVO}_{2}$ on exercise 50-60\% predicted, mildly impaired ventricular function or moderate AVVR.

(3) Very high risk - women with at least one of poor functional status (NYHA III - IV), Fontan-related complications (recurrent atrial or ventricular arrhythmias necessitating ongoing medical treatment, ongoing thromboembolic complication, liver cirrhosis, protein-losing enteropathy or plastic bronchitis) or evidence of a failing Fontan (clinical evidence of a

Table 2 Proposed risk stratification model for pregnant women with Fontan circulation. Women allocated to 'intermediate' or 'very high risk' groups based on achieving $\geq 1$ criteria for that group

\begin{tabular}{|c|c|c|c|}
\hline & $\begin{array}{l}\text { Lower } \\
\text { risk }\end{array}$ & $\begin{array}{l}\text { Intermediate } \\
\text { risk }\end{array}$ & $\begin{array}{l}\text { Very high } \\
\text { risk }\end{array}$ \\
\hline NYHA class & 1 & $\|$ & III-IV \\
\hline $\mathrm{SaO}_{2}(\%)$ & $\geq 94 \%$ & $90-93 \%$ & $<90 \%$ \\
\hline $\mathrm{MVO}_{2}(\mathrm{ml} / \mathrm{kg} / \mathrm{min})$ & $>60 \%$ & $50-60 \%$ & $<50 \%$ \\
\hline $\begin{array}{l}\text { Systemic ventricular } \\
\text { function impairment }\end{array}$ & none & mild & moderate/severe \\
\hline AWR & none/mild & moderate & severe \\
\hline $\begin{array}{l}\text { Fontan related } \\
\text { complications }^{a}\end{array}$ & none & none & at least one $e^{a}$ \\
\hline Failing Fontan ${ }^{\mathrm{b}}$ & no & no & yes \\
\hline
\end{tabular}

NYHA New York Heart Association classification, $\mathrm{SaO}_{2}$ arterial oxygen saturations, $\mathrm{MVO}_{2}$ peak oxygen consumption, $A V V R$ atrio-ventricular valve regurgitation. ${ }^{a}$ Fontan-related complications include atrial or ventricular arrhythmias, thromboembolic events, hepatic dysfunction, protein-losing enteropathy and/or plastic bronchitis. ${ }^{b}$ Failing Fontan is defined as low cardiac output state based on clinical assessment and/or episodes of heart failure 
low cardiac output state and/or episodes of heart failure), resting oxygen saturation $<90 \%$, severely impaired exercise capacity defined by $\mathrm{MVO} 2$ on exercise of $<50 \%$ predicted, moderate/severe ventricular dysfunction or severe AVVR.

Women were classified into lower risk, intermediate risk and very high risk. Women were allocated to 'intermediate' or 'very high risk' groups based on achieving $\geq 1$ criteria for that group.

\section{Study outcome and follow-up assessment}

For each pregnancy, pregnancy outcome, maternal death, maternal and/or fetal complications during pregnancy and gestation length were recorded. Further detailed information regarding all on-going pregnancies was collected and included, hospital stay, indication for delivery, mode of delivery and anti-coagulation regime. Urgency/indication of caesarean section (CS) was classified as emergency, semielective and elective based on the Royal College of Obstetrics and Gynaecology classification [21].

Complications were divided into maternal death, maternal cardiovascular complications, maternal obstetric complications and fetal/neonatal complications. Cardiac complications included deterioration in functional status by one class, sustained arrhythmia requiring medical intervention/hospitalisation and heart failure requiring medical treatment. Obstetric complications included significant $(\geq 500 \mathrm{ml})$ intra-uterine/vaginal bleeding either during pregnancy or immediately post-partum or requiring a blood transfusion, thromboembolic events, preeclampsia (hypertension beyond 20 weeks gestation with blood pressure $\geq 140 \mathrm{mmHg}$ systolic and $\geq 90 \mathrm{mmHg}$ diastolic and proteinuria), pregnancy-related hypertension (blood pressure as defined for pre-eclampsia without proteinuria) and HELLP syndrome (haemolysis, raised liver enzymes, low platelets). Prolonged maternal hospital stay was recorded and was defined as in-hospital stay $\geq 7$ days.

Fetal and neonatal complications included premature delivery ( $<37$ weeks gestation), small for gestational age (birth weight $<10^{\text {th }}$ customised centile), intra-uterine fetal death ( $\geq 24$ weeks gestation), neonatal death (within 1 month of birth) and neonatal cardiac congenital malformations.

Post-partum and long-term follow-up data were recorded for all women with live births including NYHA functional status, resting arterial oxygen saturations, ventricular function and cardiac events including sustained arrhythmias, heart failure, thromboembolic complications, conduction disease and Fontan-related complications (protein-losing enteropathy, plastic bronchitis and liver cirrhosis).

\section{Statistical analysis}

Statistical analysis was performed using XLSTAT (Microsoft Excel 2011). Categorical and continuous variables are expressed as numbers and percentages and as median (interquartile range), respectively. The Fisher Exact test was used to compare categorical variables, the Kruskal-Wallis test to compare ordinal variables, and the Mann-Whitney U test to compare continuous variables. The association between risk stratification and pregnancy outcomes was assessed by logistic regression analysis. $P$-value $<0.05$ (two-tailed) was considered statistically significant.

\section{Results}

Seventy eight Fontan women of reproductive age were identified and their data are outlined in Table 3. All women were offered pre-pregnancy counselling with $82 \%$ of women undergoing pre-pregnancy counselling. There were fewer pregnancies in women $<25$ years of age. Nine out of ten women who completed a pregnancy were in NYHA class I-II. Median baseline arterial oxygen saturation was 93 (92-94)\% in the ten women with live births. Eleven women suffered 32 miscarriages with none of these women achieving live births. The median oxygen saturation in this group was 92 (90-95)\%. In the 'never-pregnant' group the median arterial oxygen saturation was 93 (90-96)\% and 94 (92-95)\% in those $\geq 25$ years and those $<25$ years of age, respectively. There was no statistically significant difference in the baseline arterial oxygen saturations between the different groups (Table 3).

\section{Pregnancy outcomes}

There were 55 singleton pregnancies in 21 women. Maternal baseline (pre-pregnancy) characteristics are outlined in Table 4. Of these pregnancies there were 13 (24\%) live births in ten patients, 38 (69\%) spontaneous miscarriages $(p<0.05$ compared to live births), three (5\%) terminations and one (2\%) ectopic pregnancy. Eleven women suffered a total of 38 miscarriages (36 in the 1 st trimester, two in the 2 nd trimester). There were no intra-uterine fetal deaths after 24 weeks gestation. There were no maternal deaths.

$44 \%$ (24 out of 55 ) of pregnancies occurred in women in the proposed lower risk group, with $69 \%$ (nine) of the total livebirths. $29 \%$ [16] of pregnancies occurred in the intermediate risk group with $23 \%$ (three) live births and $27 \%$ [15] of the pregnancies occurred in the very high risk group with only $8 \%$ (one) live birth (Fig. 1). There were more pregnancies (OR 4.90, 95\% CI 1.46-16.42, $p<0.01$ ) and a trend towards a higher proportion of live births per total pregnancies for women in the group proposed to be at lower risk of pregnancy-related complications (OR 7.60, 95\% CI 1.81-31.97, $p=0.06$ ). 
Table 3 Baseline characteristics - all female Fontan patients $(n=78)$

\begin{tabular}{|c|c|c|c|c|}
\hline & \multirow{2}{*}{$\begin{array}{l}\text { Pregnant, livebirths } \\
(n=10)\end{array}$} & \multirow{2}{*}{$\begin{array}{l}\text { Pregnant, no live births } \\
(n=11)\end{array}$} & \multicolumn{2}{|l|}{ Never pregnant $(n=57)$} \\
\hline & & & Age $<25$ yrs $(n=27)$ & Age $\geq 25$ yrs $(n=30)$ \\
\hline Age (years) ${ }^{a}$ & $25(23-38)$ & $23(18-32)$ & $21(20-23)$ & $29(27-33)$ \\
\hline Age at first Fontan repair (years) & $9(3-18)$ & $7(3-12)$ & $4(2-13)$ & $6(5-9)$ \\
\hline Time since first Fontan repair (years) & $14(11-16)$ & $17(13-19)$ & $17(14-20)$ & $25(21-26)^{b}$ \\
\hline \multicolumn{5}{|l|}{ Fontan type, n (\%) } \\
\hline Atrio-pulmonary & $5(50)$ & $8(73)$ & $6(22)$ & $21(70)$ \\
\hline Lateral tunnel & $3(33)$ & $3(27)$ & $2(7)$ & $2(7)$ \\
\hline Extra-cardiac & $1(10)$ & $0(0)$ & $19(70)$ & $4(13)^{c}$ \\
\hline Other & $1(10)$ & $0(0)$ & $0(0)$ & $3(10)$ \\
\hline \multicolumn{5}{|l|}{ Functional status, n (\%) } \\
\hline NYHA I & $5(50)$ & $3(27)$ & $7(26)$ & $9(30)$ \\
\hline NYHA ॥ & $4(40)$ & $7(64)$ & $19(70)$ & $14(47)$ \\
\hline NYHA III & $1(10)$ & $1(9)$ & $1(4)$ & $6(20)$ \\
\hline NYHA IV & $0(0)$ & $0(0)$ & $0(0)$ & $1(3)$ \\
\hline \multicolumn{5}{|l|}{ Oxygen saturations, n (\%) } \\
\hline$<85 \%$ & $0(0)$ & $0(0)$ & $0(0)$ & $2(7)$ \\
\hline $85-89 \%$ & $1(10)$ & $2(18)$ & $4(15)$ & $2(7)$ \\
\hline$>90 \%$ & $9(90)$ & $9(81)$ & $23(85)$ & $26(87)$ \\
\hline \multicolumn{5}{|l|}{ Ventricular function, n (\%) } \\
\hline Good & $10(100)$ & $6(54)$ & $23(85)$ & $22(73)$ \\
\hline Mildly impaired & $0(0)$ & $3(27)$ & $2(7)$ & $4(13)$ \\
\hline Moderately impaired & $0(0)$ & $1(9)$ & $2(7)$ & $2(7)$ \\
\hline Severely impaired & $0(0)$ & $1(9)$ & $0(0)$ & $2(7)$ \\
\hline \multicolumn{5}{|l|}{ Fontan-related complications, n (\%) } \\
\hline Arrhythmias & $0(0)$ & $2(18)$ & $2(7)$ & $14(47)$ \\
\hline Conduction disease & $0(0)$ & $0(0)$ & $2(7)$ & $5(17)$ \\
\hline Significant valvar dysfunction & $0(0)$ & $2(18)$ & $5(19)$ & $8(27)$ \\
\hline Thromboembolism & $0(0)$ & $0(0)$ & $1(4)$ & $5(17)$ \\
\hline Liver cirrhosis & $0(0)$ & $0(0)$ & $0(0)$ & $1(3)$ \\
\hline PLE & $0(0)$ & $0(0)$ & $1(4)$ & $1(3)$ \\
\hline \multicolumn{5}{|l|}{ Associated morbidity, n (\%) } \\
\hline Learning difficulties & $0(0)$ & $0(0)$ & $0(0)$ & $1(3)$ \\
\hline Chromosomal abnormalities & $0(0)$ & $0(0)$ & $0(0)$ & $0(0)$ \\
\hline Pre-pregnancy counselling, n (\%) & $7(70)$ & $10(91)$ & $22(81)$ & $28(93)$ \\
\hline
\end{tabular}

${ }^{a}$ Age was determined at time of pregnancy or at time of counselling for the women who never had a pregnancy. NYHA New York Heart Association classification, PLE protein-losing enteropathy. ${ }^{b}$ Significant difference in time from first Fontan repair in non-pregnant vs pregnant and non-pregnant vs women with live births. 'Significant difference between number of extra-cardiac Fontan patients in pregnant vs never pregnant Fontan women ( $p<0.05$ ). Continuous data is expressed as median (interquartile range)

There was a trend towards the highest rate of miscarriage (including one termination and one ectopic pregnancy) in the proposed very high risk group (93.3\%, 14 out of 15 pregnancies) vs $81.2 \%$ (13 out of 16 pregnancies, intermediate group) vs $62.5 \%$ (15 out of 24 pregnancies, lower risk group, $p=0.07$ compared to the high risk group).
Five live-birth pregnancies resulted in a prolonged hospital stay ( $\geq 7$ days) until delivery. In four cases, this was due to maternal cardiovascular reasons and in one case due to obstetric reasons. Of the 13 live births, median gestational age was 32 (range 30-34) weeks, with 12 out of 13 pregnancies delivered prematurely. No woman in our cohort had an uncomplicated spontaneous labour. Indications 
Table 4 Pregnancy outcomes in women with a Fontan circulation

\begin{tabular}{|c|c|}
\hline \multicolumn{2}{|l|}{ All pregnancy outcomes - 55 patients, $n(\%)$} \\
\hline Live births & $13(24)$ \\
\hline Spontaneous miscarriage & $38(69)^{*}$ \\
\hline Termination & $3(5)$ \\
\hline Ectopic pregnancy & $1(2)$ \\
\hline \multicolumn{2}{|l|}{ Live birth outcomes ( $n=13$ ) } \\
\hline Median gestational age of live birth (weeks) & $32(30-34)^{a}$ \\
\hline \multicolumn{2}{|l|}{ Mode of delivery, $n(\%)$} \\
\hline Vaginal delivery & $1(8)$ \\
\hline Emergency CS & $3(23)$ \\
\hline Semi-elective CS & $9(69)^{b}$ \\
\hline \multicolumn{2}{|l|}{ Indication for delivery, $n(\%)$} \\
\hline Maternal CVS & $5(38)$ \\
\hline Maternal obstetric & $4(31)$ \\
\hline Fetal & $4(31)$ \\
\hline Total all-cause prolonged hospitalisation, $n(\%)$ & $5(38)$ \\
\hline Cardiac & $4(31)$ \\
\hline Obstetric & $1(8)$ \\
\hline \multicolumn{2}{|l|}{ Maternal CVS complications, $n(\%)$} \\
\hline Significant deterioration in symptoms & $8(62)$ \\
\hline Heart failure/low cardiac output state & $2(15)$ \\
\hline Arrhythmias & $2(15)$ \\
\hline \multicolumn{2}{|l|}{ Maternal obstetric complications, $n$ (\%) } \\
\hline Ante-partum haemorrhage & $3(23)$ \\
\hline Post-partum haemorrhage & $2(15)$ \\
\hline Retro-placental haematoma & $1(8)$ \\
\hline Pre-eclampsia & $0(0)$ \\
\hline Pregnancy-induced hypertension & $0(0)$ \\
\hline \multicolumn{2}{|l|}{ Fetal/neonatal complications, $n(\%)$} \\
\hline Birth weight (g) & $1480(1225-1815)^{\mathrm{a}}$ \\
\hline Fetal distress & $3(23)$ \\
\hline No. of premature deliveries & $12(92)$ \\
\hline Prematurity 33-36 weeks & $4(31)$ \\
\hline Prematurity $28-32$ weeks & $7(53)$ \\
\hline Prematurity $<28$ weeks & $1(8)$ \\
\hline SGA & $3(23)$ \\
\hline Congenital heart disease & $2(15)$ \\
\hline Developmental delay & $2(15)$ \\
\hline
\end{tabular}

CVS cardiovascular, CS caesarean section, SGA small for gestational age - birth weight $<10^{\text {th }}$ centile. ${ }^{\text {aC }}$ Continuous data is presented as median (inter-quartile range). ${ }^{*} p<0.05$ compared to live births. ${ }^{\mathrm{b}} \mathrm{A}$ semi-elective CS was classified as those women requiring early delivery $(<37$ weeks gestation) due to maternal or fetal reasons, but without an immediate risk to life for delivery were due to either maternal cardiovascular (38\%), maternal obstetric (31\%) or fetal reasons (31\%).

\section{Maternal cardiovascular complications during pregnancy}

Of the 13 live-birth pregnancies in ten women, the majority of the women (eight out of $13,62 \%$ ) described an increase in symptoms e.g. breathless, fatigue and/or limited exercise tolerance (Table 4). In four (31\%) pregnancies in three women, there was a significant deterioration in functional class, necessitating treatment with diuretics and hospital admission - one with heart failure and sustained arrhythmia requiring intervention/hospitalisation and later an implantable cardiac defibrillator. Two further pregnancies (in two women) were complicated by atrial arrhythmias, requiring treatment with electrical cardioversion and beta-blockers.

In the pregnant women who did not experience a live birth (42/55 pregnancies with 41 pregnancies ending in the 1st trimester), there were no maternal cardiovascular complications.

\section{Maternal obstetric complications during pregnancy}

In four out of 13 (31\%) live birth pregnancies, there was vaginal (PV) bleeding requiring hospital admission. In all of these cases, the baby was delivered by CS, with two women having pre-term CS as a direct result of the bleeding.

Three further women (whose pregnancies did not result in a live birth) suffered spontaneous miscarriages associated with PV bleeding - at 12, 16, and 23 weeks gestation. One woman required a blood transfusion.

There were no cases of thrombo-embolic complications during pregnancy. One woman suffered a minor embolic cerebrovascular event three weeks post-partum despite therapeutic anticoagulation. She made a full recovery.

\section{Anti-coagulation}

Twenty out of 21 women received anticoagulation with warfarin prior to pregnancy. One woman was not on anticoagulation due to poor compliance. She suffered three $1^{\text {st }}$ trimester miscarriages whilst not taking warfarin, and had no live births.

In 52 out of 55 pregnancies, warfarin was converted to low-molecular weight heparin (LMWH, enoxaparin $1 \mathrm{mg} / \mathrm{kg}$ twice daily) on confirmation of pregnancy, and continued for the duration of the pregnancy. Dosing regimen was as per Royal College of Obstetrics and Gynaecology guidelines and supervised by a haematologist with expertise of managing anticoagulation during pregnancy [13]. The remaining four women suffered early $1^{\text {st }}$ trimester spontaneous miscarriages, prior to conversion to LMWH. 

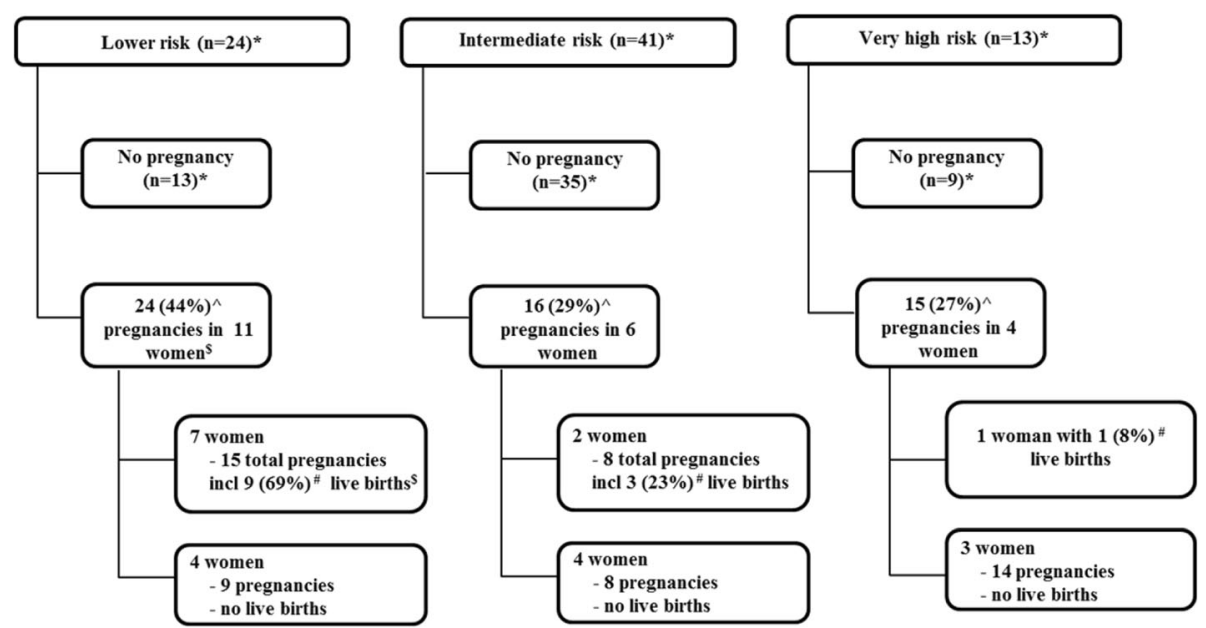

Fig. 1 Risk stratification of pregnancy-related maternal morbidity and/or mortality in 78 Fontan women. ${ }^{*} n=$ number of women. $\wedge=\%$ of total pregnancies $(n=55)$. Incl = including. \# = \% of total live births $(n=13) . \$=$ Higher proportion of pregnancies (OR 4.90, 95\% Cl 1.46-16.42, $p \leq 0.01)$ and live births $(\mathrm{OR} 7.60,95 \% \mathrm{Cl} 1.81-31.97, p=0.06)$ in women at lower risk

\section{Neonatal complications during pregnancy}

Twelve out of $13(92 \%)$ of the live births resulted in pre-term delivery $(<37$ weeks gestation). Four $(31 \%)$ of the deliveries occurred between 33-36 weeks gestation, seven $(53 \%)$ between $28-32$ weeks gestation and one $(8 \%)$ of the live births occurred at 28 weeks gestation (Table 4).

There was one $2^{\text {nd }}$ trimester intrauterine death, complicated by placental bleeding requiring a blood transfusion. Fetal post-mortem revealed small-sized organs and no congenital or chromosomal abnormality.

Two women underwent CS at 31 and 34 weeks gestation for intra-uterine fetal growth restriction (small for gestational, age estimated fetal weight $<10^{\text {th }}$ customised centile) - one of these women was significantly cyanosed with pre-pregnancy resting oxygen saturations of $88 \%$. Neither of these women had been treated with beta-blockers during their pregnancy.

Mode of delivery is shown in Table 4. One woman had a vaginal delivery at 35 weeks gestation, three women had an emergency CS at 30, 31 and 39 weeks, and nine women had semi-elective CS (requiring early delivery but no immediate maternal or fetal compromise).

Five out of 13 neonates experienced an adverse outcome including cardiac congenital lesion $(n=2)$, significant bradycardia secondary to maternal beta blocker use $(n=1)$, SGA $(n=3)$ and developmental delay $(n=2)$. Two infants had congenital heart defects and neither required immediate cardiac intervention. Two neonates had cerebral palsy - one born at 30 weeks gestation and the other at 34 weeks. There were no neonatal deaths.

\section{Cardiovascular status at follow-up - post-partum and long-term}

Thirteen post-partum clinic reviews were undertaken eight (5-11) weeks after delivery (Table 5). The majority of women reported return of symptoms back to baseline, with 11 out of 13 reports of NYHA class I - II symptoms. Despite therapeutic anticoagulation, one woman suffered a confirmed embolic cerebrovascular accident three weeks post-partum. One woman (who underwent two pregnancies) had a significant and permanent deterioration of ventricular function following the first pregnancy.

Late follow-up data with a median of $4.8(3.3-10)$ years were available for nine out of ten women. One woman had recently given birth and therefore no long-term postpregnancy data were available. There had been a deterioration in functional class from NYHA I to III in two women who had completed pregnancies. Both of these women had deterioration of ventricular function during pregnancy. Pre-pregnancy ventricular function was normal in both of these women and was moderately impaired in one woman and severely impaired in the second woman.

Five out of nine (56\%) women with no prior arrhythmia had developed arrhythmia at the latest follow-up. Two women had developed a 'failing Fontan' state. One of these women had been in the proposed intermediate risk group and the other in the very high risk group, at time of pre-pregnancy counselling. Thromboembolic complications $(n=1)$, and significant conduction disease $(n=2)$ were also seen. 
Table 5 Follow-up data of women with live births

\begin{tabular}{|c|c|c|}
\hline & $\begin{array}{l}\text { Initial post-partum } \\
\text { follow-up after each } \\
\text { pregnancy }(n=13)\end{array}$ & $\begin{array}{l}\text { Late follow-up, } \\
\text { each patient } \\
(n=9)^{\mathrm{a}}\end{array}$ \\
\hline Time to follow-up & $8(5-11)$ weeks & $\begin{array}{l}4.8(3.3-10) \\
\text { years }\end{array}$ \\
\hline Functional status & N (\%) & N (\%) \\
\hline NYHA I & $5(38)$ & $2(22)$ \\
\hline NYHA II & $6(46)$ & $5(56)$ \\
\hline NYHA III & $2(15)$ & $1(11)$ \\
\hline NYHA IV & $0(0)$ & $1(11)$ \\
\hline \multicolumn{3}{|l|}{ Arterial oxygen saturations } \\
\hline $85-89 \%$ & $3(23)$ & $2(22)$ \\
\hline$>90 \%$ & $10(77)$ & $7(78)$ \\
\hline \multicolumn{3}{|l|}{ Post-pregnancy ventricular function } \\
\hline Good & $11(84)$ & $7(78)$ \\
\hline Mildly impaired & $1(8)$ & $0(0)$ \\
\hline Moderately impaired & $1(8)$ & $1(11)$ \\
\hline Severely impaired & $0(0)$ & $1(11)$ \\
\hline Arrhythmias & $0(0)$ & $5(56)$ \\
\hline Thromboembolic complications & $1(8)$ & $1(11)$ \\
\hline Heart failure & $1(8)$ & $1(11)$ \\
\hline Failing Fontan & $0(0)$ & $2(22)$ \\
\hline $\begin{array}{l}\text { Conduction disease requiring } \\
\text { PPM }\end{array}$ & $0(0)$ & $2(22)$ \\
\hline
\end{tabular}

NYHA New York Heart Association classification, PPM permanent pacemaker; ${ }^{a}$ One patient had no late follow-up data due to very recent pregnancy

\section{Discussion}

With an improvement in survival following Fontan palliation, we may expect to see an increase in the number of Fontan women wanting to become pregnant. In our cohort of 78 women with a Fontan circulation, those with a shorter duration since Fontan repair were more likely to achieve a pregnancy compared to the women ( $\geq 25$ years) who had a longer duration since Fontan repair. As might be expected, this latter group of women had a greater number of Fontan-related complications. In the lower age group ( $<25$ years) other factors such as relationship status and youth may also have been more likely to influence the decision to not pursue pregnancy.

We observed a high rate of spontaneous miscarriages (69\%), cardiovascular morbidity (62\%) and preterm delivery (92\%). These pregnancies were predominantly in a group of 'well-functioning' Fontan patients. The high miscarriage rate in women with a Fontan heart is well described [7]. The cause of the high spontaneous miscarriage is unclear. Previous reports suggest an association between hypoxia and spontaneous miscarriages; however this was not borne out by our data [22].

Antepartum and postpartum haemorrhage was the main cause of obstetric complications in our series, and was similar to the $50 \%$ described by Cauldwell et al. [7] In both studies, women received therapeutic or prophylactic low molecular weight heparin that was paused at delivery [13]. In contrast, in the series from the Mayo clinic [8], the majority of women received no anticoagulation or aspirin during pregnancy and suffered no significant haemorrhagic or thromboembolic complications. These important differences suggest that approaches to anticoagulation in pregnant women with a Fontan circulation require further study and may need to be reconsidered.

In contrast to published series, we observed a high rate of pre-term delivery (92\%) and a higher rate of CS delivery $[7,8,10]$. The latter may be attributed to a higher rate of maternal and fetal morbidity seen in our cohort necessitating delivery rather than allowing spontaneous labour to take place. CS was the mode of delivery chosen for these women for preterm delivery to avoid risk of an emergency CS following failed induction, the risks of which would have been particularly high in this patient group [23].

Scoring systems to estimate maternal cardiovascular risk for women with heart disease attribute a high risk of adverse outcome for women with the Fontan circulation $[14,16,17,24]$. This risk is further increased with poor pre-pregnancy cardiovascular status (poor functional class and hypoxia) and in the presence of other complications such as thromboembolic disease or arrhythmias $[14,15,22]$. Our data show for the first time a trend towards livebirth rate being affected by maternal cardiovascular status - women with the worst cardiovascular status had a higher rate of miscarriage (93.3\%) than those with good cardiovascular status (62.5\%). Similarly, there was a trend towards a higher live birth rate in the lower risk group, with only one live birth in the veryhigh risk group. These data require validation in larger studies as they may provide a useful framework in informing pre-pregnancy counselling to be further refined to counsel women appropriately, i.e. women with the highest risk of complications during pregnancy may also be at the highest risk of miscarriage and have the lowest chance of having a pregnancy resulting in a live birth.

Our long-term follow-up data (median 4.8 years) demonstrated that Fontan complications were common in the years after pregnancy, and included atrial arrhythmia and heart failure. In this study, it is not possible to determine whether these complications were precipitated by pregnancy or occurred as part of the natural history of a Fontan circulation. Although it is difficult to draw firm conclusions from this dataset, our experience in a small number of individual women suggests that any deterioration in cardiac function that occurs during pregnancy may not recover. 


\section{Strengths and limitations}

A major strength of this study is that all the patients are followed up at a single institution with a complete dataset of information available for the patients included in the analysis. The study is limited by the retrospective nature of data collection. The small sample size limits the conclusions that can be drawn, particularly in relation to subgroup analysis. There may have been differences in the way pre-pregnancy counselling was delivered that may have affected patients' decision-making. However, since 2001 the management of these patients has been undertaken by the same team of doctors thus minimising such inconsistencies.

In Fontan hearts, echocardiographic measure of ventricular function may be variable due to the variability in ventricular geometry and morphology. In our department, assessment of ventricular function is based on quantitative as well as qualitative measures, as described previously. However, there is likely to be inherent inter and intra observer variability in the reported ventricular function which may limit accurate assessment.

\section{Conclusions}

Women with a Fontan circulation who wish to become pregnant are at high risk of miscarriage, fetal complications and major obstetric and cardiovascular maternal morbidity. These women need specialised pre-pregnancy assessment, counselling and antenatal care. We have proposed an innovative risk-scoring system to identify Fontan women at greatest risk of a poor obstetric prognosis which may allow tailoring of pre-pregnancy counselling. Women with the poorest pre-pregnancy cardiovascular status should be advised that they are particularly unlikely to achieve a successful pregnancy. Women with good functional status may be more likely to achieve a live birth, but still face a high miscarriage and complication rate.

\section{Abbreviations \\ ACHD: Adult Congenital Heart Disease; AWR: Atrioventricular valve regurgitation; CARPREG: Cardiac disease in Pregnancy; CHD: Congenital Heart disease; CO: Cardiac output; CS: Caesarean section; HELLP: Haemolysis, raised liver enzymes, low platelets; LMWH: Low-molecular weight heparin; MVO2: Myocardial oxygen consumption; NYHA: New York Heart Association; OR: Odds ratio; PV: Per vaginal; SGA: Small for gestational age; WHO: World Health Organisation; ZAHARA: Zwangerschap bij Aangeboren HARtAfwijkingen}

\section{Acknowledgements}

The author's would like to thank Peter Nightingale for his help with the statistical analyses and Elaine Smith for her help with collating the medical records.

\section{Funding}

None sought.

\section{Availability of data and materials}

The datasets generated and/or analysed during the current study are not publicly available as they contain patient identifiable information and information that is clinically confidential. However anonymised data are available from the corresponding author on reasonable request.

\section{Authors' contributions}

SA and ST conceived the idea. SA and AC collected the data. SA and SAT analysed the data. The initial draft of the article was written by SA and $A C$ but all of the authors (SA, AC, KM, TS, SB, LH, PC, PT and SAT) assessed and edited the manuscript. All of the authors read and approved the final manuscript.

\section{Ethics approval and consent to participate}

This retrospective review was undertaken as part of clinical service evaluation and adhered to local audit protocols, therefore ethical approval and written, informed consent from patients was not sought.

\section{Consent for publication}

Not applicable

\section{Competing interests}

The authors declare that they have no competing interests.

\section{Publisher's Note}

Springer Nature remains neutral with regard to jurisdictional claims in published maps and institutional affiliations.

\section{Author details}

${ }^{1}$ Queen Elizabeth Hospital Birmingham NHS Trust, Birmingham B15 2TH, UK. Birmingham Women's and Children's Hospital NHS Foundation Trust, Birmingham B15 2TG, UK. ${ }^{3}$ Institute of Metabolism and Systems Research, Centre for Womens and Newborn Health, Birmingham Health Partners, University of Birmingham, Birmingham B15 2TT, UK.

Received: 3 July 2017 Accepted: 14 November 2017

Published online: 08 December 2017

\section{References}

1. Gewillig M. The Fontan circulation. Heart. 2005;91(6):839-46.

2. Fontan F, Kirklin JW, Fernandez G, Costa F, Naftel DC, Tritto F, et al. Outcome after a "perfect" Fontan operation. Circulation. 1990;81(5):1520-36.

3. Coats L, O'Connor S, Wren C, O'Sullivan J. The single-ventricle patient population: a current and future concern a population-based study in the North of England. Heart. 2014;100(17):1348-53.

4. Hunter S, Robson SC. Adaptation of the maternal heart in pregnancy. $\mathrm{Br}$ Heart J. 1992;68(6):540-3.

5. Le Gloan L, Mercier LA, Dore A, Marcotte F, Mongeon FP, Ibrahim R, et al. Pregnancy in women with Fontan physiology. Expert Rev Cardiovasc Ther. 2011;9(12):1547-56

6. Canobbio MM, Mair DD, van der Velde M, Koos BJ. Pregnancy outcomes after the Fontan repair. J Am Coll Cardiol. 1996;28(3):763-7.

7. Cauldwell M, Von Klemperer K, Uebing A, Swan L, Steer PJ, Babu-Narayan SV, et al. A cohort study of women with a Fontan circulation undergoing preconception counselling. Heart. 2016;102(7):534-40.

8. Pundi KN, Pundi K, Johnson JN, Dearani JA, Bonnichsen CR, Phillips SD, et al. Contraception practices and pregnancy outcome in patients after fontan operation. Congenit Heart Dis. 2016;11(1):63-70.

9. Zentner D, Kotevski A, King I, Grigg L, dU Y. Fertility and pregnancy in the Fontan population. Int J Cardiol. 2016;208:97-101.

10. Gouton M, Nizard J, Patel M, Sassolas F, Jimenez M, Radojevic J, et al. Maternal and fetal outcomes of pregnancy with Fontan circulation: a multicentric observational study. Int J Cardiol. 2015;187:84-9.

11. Hoare JV, Radford D. Pregnancy after fontan repair of complex congenital heart disease. Aust N Z J Obstet Gynaecol. 2001;41(4):464-8.

12. Drenthen W, Pieper PG, Roos-Hesselink JW, van Lottum WA, Voors AA, Mulder BJ, et al. Pregnancy and delivery in women after Fontan palliation. Heart. 2006;92(9):1290-4

13. Siu SC, Colman JM, Sorensen S, Smallhorn JF, Farine D, Amankwah KS, et al. Adverse neonatal and cardiac outcomes are more common in pregnant women with cardiac disease. Circulation. 2002;105(18):2179-84.

14. Siu SC, Sermer M, Colman JM, Alvarez AN, Mercier LA, Morton BC, et al. Prospective multicenter study of pregnancy outcomes in women with heart disease. Circulation. 2001:104(5):515-21.

15. Regitz-Zagrosek V, Blomstrom Lundqvist C, Borghi C, Cifkova R, Ferreira R, Foidart JM, et al. ESC Guidelines on the management of cardiovascular diseases during pregnancy: the Task Force on the Management of 
Cardiovascular Diseases during Pregnancy of the European Society of Cardiology (ESC). Eur Heart J. 2011;32(24):3147-97.

16. Thorne S, MacGregor A, Nelson-Piercy C. Risks of contraception and pregnancy in heart disease. Heart. 2006;92(10):1520-5.

17. Drenthen W, Boersma E, Balci A, Moons P, Roos-Hesselink JW, Mulder BJ, et al. Predictors of pregnancy complications in women with congenital heart disease. Eur Heart J. 2010;31(17):2124-32.

18. The Criteria Committee of the New York Heart Association. Nomenclature and Criteria for Diagnosis of Diseases of the Heart and Great Vessels: 9th edition. Boston, MA, USA: Little, Brown \& Co; 1994. 253-6 p.

19. Rios R, Ginde S, Saudek D, Loomba RS, Stelter J, Frommelt P. Quantitative echocardiographic measures in the assessment of single ventricle function post-Fontan: Incorporation into routine clinical practice. Echocardiography. 2017;34(1):108-15.

20. Masani N, Wharton G, Allen J, Chambers J, Graham J, Jones R, et al. Echocardiography: Guidelines for Chamber Quantification. Guideline. London: British Society of Echocardiography; 2011.

21. Steer P. Royal College of Obstetricians and Gynaeoclogists Good Practice Guidance 13: Cardiac Disease in Pregnancy. Royal College of Obstetricians and Gynaecologists: London; 2011.

22. Presbitero P, Somerville J, Stone S, Aruta E, Spiegelhalter D, Rabajoli F. Pregnancy in cyanotic congenital heart disease. Outcome of mother and fetus. Circulation. 1994;89(6):2673-6.

23. Seyb ST, Berka RJ, Socol ML, Dooley SL. Risk of cesarean delivery with elective induction of labor at term in nulliparous women. Obstet Gynecol. 1999:94(4):600-7.

24. Goya M, Casellas M, Merced C, Pijuan-Domenech A, Galian L, Dos L, et al. Predictors of obstetric complications in women with heart disease. J Matern Fetal Neonatal Med. 2016;29(14):2306-11.

\section{Submit your next manuscript to BioMed Central and we will help you at every step:}

- We accept pre-submission inquiries

- Our selector tool helps you to find the most relevant journal

- We provide round the clock customer support

- Convenient online submission

- Thorough peer review

- Inclusion in PubMed and all major indexing services

- Maximum visibility for your research

Submit your manuscript at www.biomedcentral.com/submit 